\title{
Impact-Echo Method Used to Testing of High Temperature Degraded Concrete Composite of Portland Cement CEM I 42.5 R and Gravel Aggregate 8/16
}

\author{
Richard Dvořák ${ }^{1, a}$, Miroslav Luňák ${ }^{1, b}$, Zdeněk Chobola ${ }^{c}$, Rudolf Hela, Lenka \\ Bodnárová
}

${ }^{1}$ Institute of Physics, Faculty of civil engineering, Brno University of Technlogy, Veveří 331/95, Brno 602 00, Czech Republic

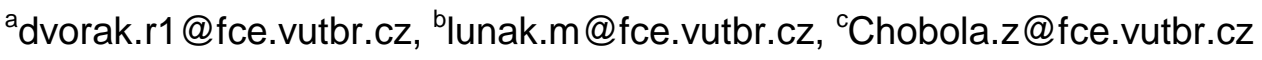

Keywords: Impact-echo method, Concrete, High-temperature degradation, Longitudinal waves.

\begin{abstract}
In this article, we showed possibility to use Impact-echo acoustic method to testing concrete degraded by high temperature. The results are compared with traditional parameter such as flexural bending strength. We observed longitudinal waves.
\end{abstract}

\section{Introduction}

The present paper examines the potential applicability of the Impact-echo method for analyzing the specimens made from a concrete composite material, which were intentionally degraded by high-temperature treatment to $1200{ }^{\circ} \mathrm{C}$.

Acoustic techniques are very often used to evaluate concrete $[1,2]$. The impact-echo method is based on the application of a short-duration stress pulse on the concrete surface by a mechanical impact. Then follows analyzing an elastic-impulse-induced mechanical wave [3]. A short-time mechanical impulse, which is induced by a steel spherical body tapping the test specimen surface, gives rise to a low-frequency pressure wave. Thus generated wave propagates throughout the specimen structure being rebounded by defects located in the specimen bulk or in the surface. The time difference between the emitted wave and the rebounded one is captured by a sensor, which shows the signal waveform $[4,5]$. This signal describes transient local vibrations, which are caused by the mechanical wave multiple reflection inside the structure.

The dominant frequencies of these vibrations give an account of the condition of the structure, at which the waves are rebounded [6]. As a rule, the signal is digitized by means of a data processing system to be transferred into a computer memory. The signal is further processed to gibe rise, for example, to a frequency spectrum. Peaks in this spectrum represent resonance frequencies in the curve and can be used for assessing the condition of the structure under investigation.

\section{The Specimens}

For our research we have prepared concrete samples with dimensions of $0.1 \mathrm{~m}$ x $0.1 \mathrm{~m} \times 0.4 \mathrm{~m}$. Specimens type A were prepared according to the following mix design (for $1 \mathrm{~m} 3$ ): $345 \mathrm{~kg}$ Portland cement CEM I 42.5 R Mokrá, $848 \mathrm{~kg}$ quartz sand 0/4 mm Zabcice, $980 \mathrm{~kg}$ gravel aggregate 8/16 Olbramovice, $2.8 \mathrm{~kg}$ super-plasticizer Sika Viscocrete 2030 and $160 \mathrm{~kg}$ water. Consistency F4 (Flow, $550 \mathrm{~mm}$ ). Samples were compacted in form for 10 second on a vibrating table a frequency of $30 \mathrm{~Hz}$. The specimens were manufactured by prof. Hela in Institute of Technology of Building Materials and Components. The specimens were 28 days soaked in water and then dried at first in the laboratory temperature and then 48 hours in a ceramic furnace at temperature $110{ }^{\circ} \mathrm{C}$. The concrete specimens were heated in programmable laboratory furnace Rhode KE $130 \mathrm{~B}$ at the heating rate of $5{ }^{\circ} \mathrm{C} / \mathrm{min}$ (Fig. 1). Selected temperature $\mathrm{T}=200{ }^{\circ} \mathrm{C}, 400{ }^{\circ} \mathrm{C}, 600{ }^{\circ} \mathrm{C}, 800{ }^{\circ} \mathrm{C}, 1000{ }^{\circ} \mathrm{C}$ and $1200{ }^{\circ} \mathrm{C}$ were maintained for 60 minutes. 


\section{Experiment}

To generate the signal, a hammer of a mass of $70.5 \mathrm{~g}$, originally suspended from a hanger, was released to fall on the specimen from a height of $4 \mathrm{~cm}$. The response was picked up by an S3 type piezoelectric sensor whose output voltage was fed into Yokogawa 1540-CL four-channel, digital, eight-bit oscilloscope (Fig. 2). Being processed and displayed by the oscilloscope, the signal was evaluated by means of AE-proc package [7].

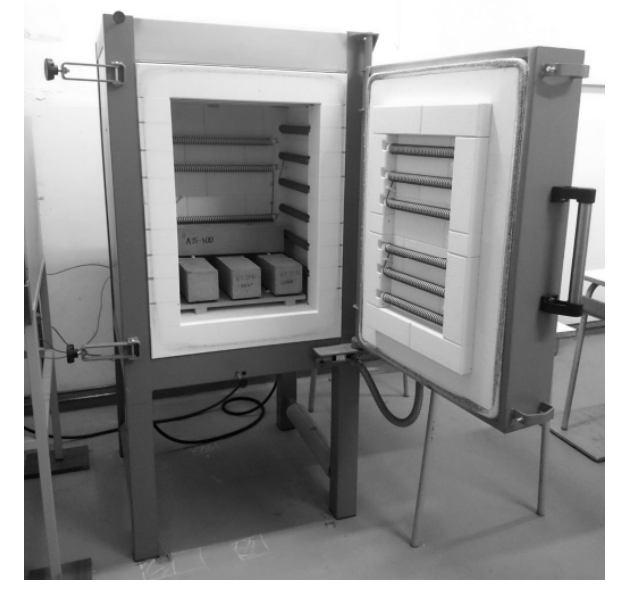

Fig. 1 Programmable furnace Rhode KE 130B.

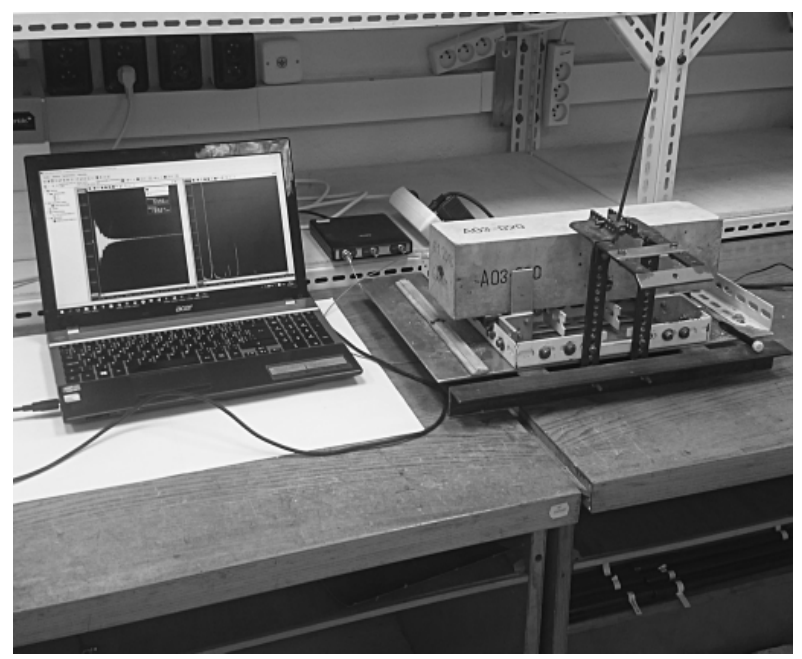

Fig. 2 The arrangement of experiment.

\section{Measurements Results}

Fig. 3 shows a record of the frequency spectrum measurement taken for a specimen by temperature of $20{ }^{\circ} \mathrm{C}$ (this specimen has not been subjected to any elevated-temperature load test). The sensor was placed at the center of the specimen shorter side. The hammer tapped the specimen at the opposite side in the longitudinal center line direction. The measurement run was labelled UB0. We measured the longitudinal waves. We observed dominant frequency $\mathrm{f}=5220 \mathrm{~Hz}$. Considering the length of sample, we get the wave propagation velocity to equal $4176 \mathrm{~ms}^{-1}$.

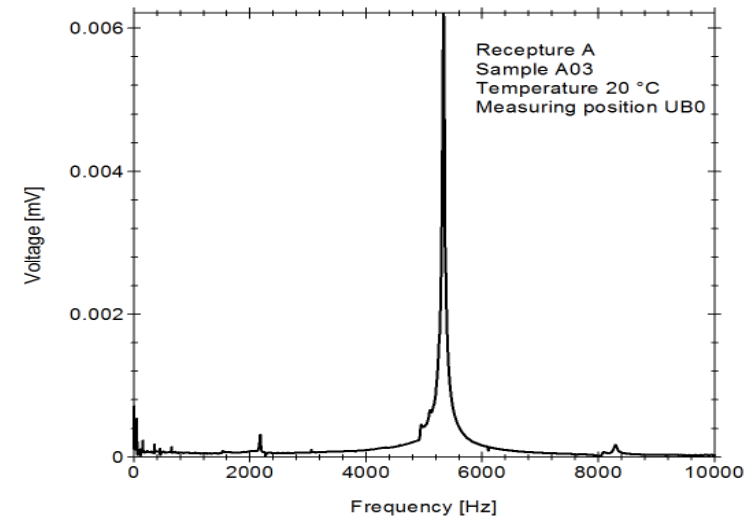

Fig. 3 Frequency spectrum of Sample A03, temperature $20^{\circ} \mathrm{C}$.

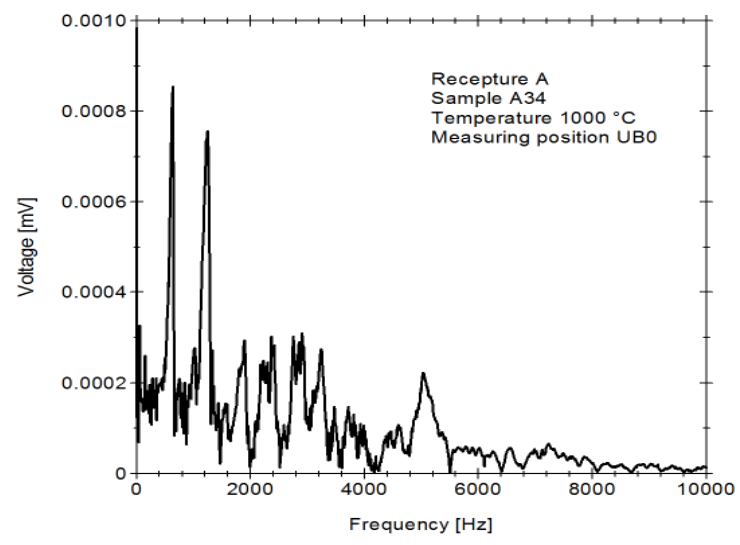

Fig. 4 Frequency spectrum of Sample A34, after degradation by temperature $1000^{\circ} \mathrm{C}$.

Fig. 4 shows a frequency spectrum record for the specimen which underwent thermal stressing at a temperature of $1000{ }^{\circ} \mathrm{C}$. It is seen that the predominant frequencies shifted down towards the 
lower frequency region, namely, to $\mathrm{f}=890 \mathrm{~Hz}$.

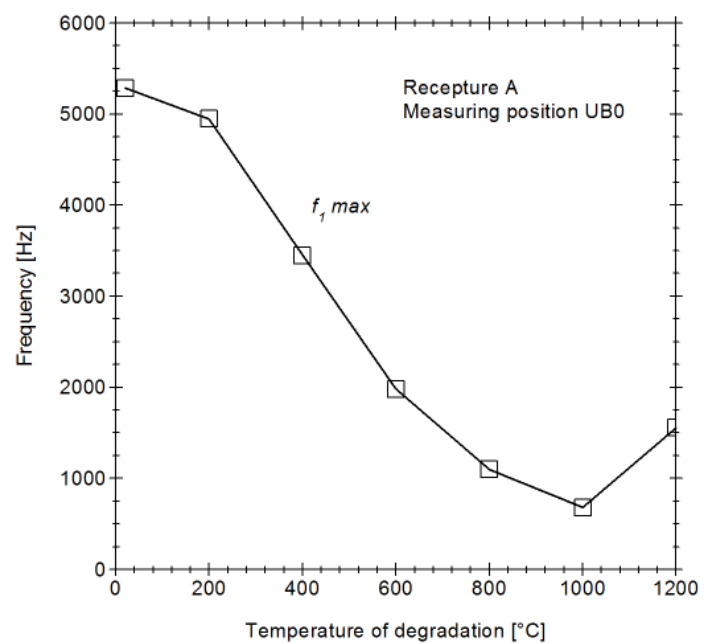

Fig. 5 Shift of dominant frequencies due to degradation by high temperature.
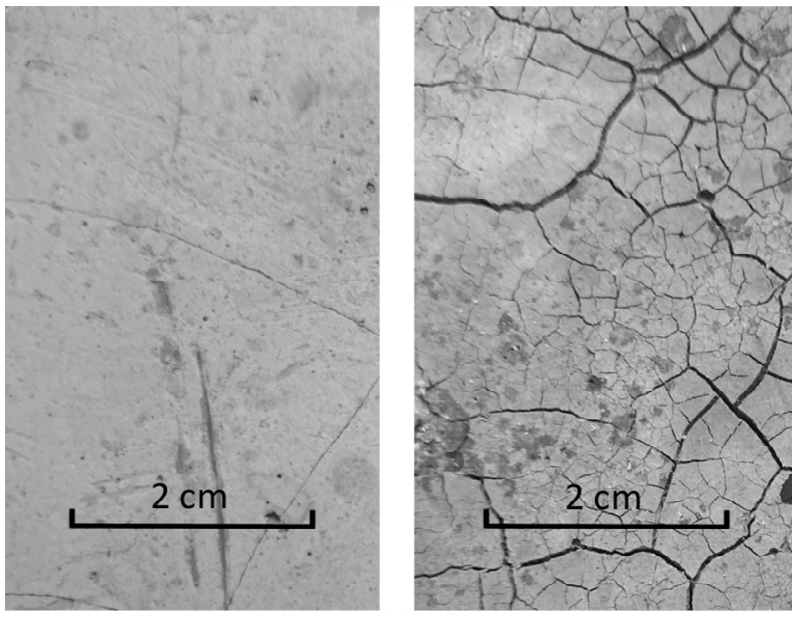

Fig. 6 Specimen surface before and after temperature degradation at $1200{ }^{\circ} \mathrm{C}$ (on the right).

Fig. 5 illustrates the change in predominant frequencies versus the specimen stressing temperatures. Dominant frequencies are shifting towards to the lower frequency range during the degradation. The decrease is rather slow at temperatures of up to $600{ }^{\circ} \mathrm{C}$, to speed up above this temperature. This is due to the phase transformation of quartz at $573{ }^{\circ} \mathrm{C}$. The predominant frequencies are growing up at temperatures above $1000{ }^{\circ} \mathrm{C}$. This is due to the specimen structural changes, because new crystalline phases are arising.

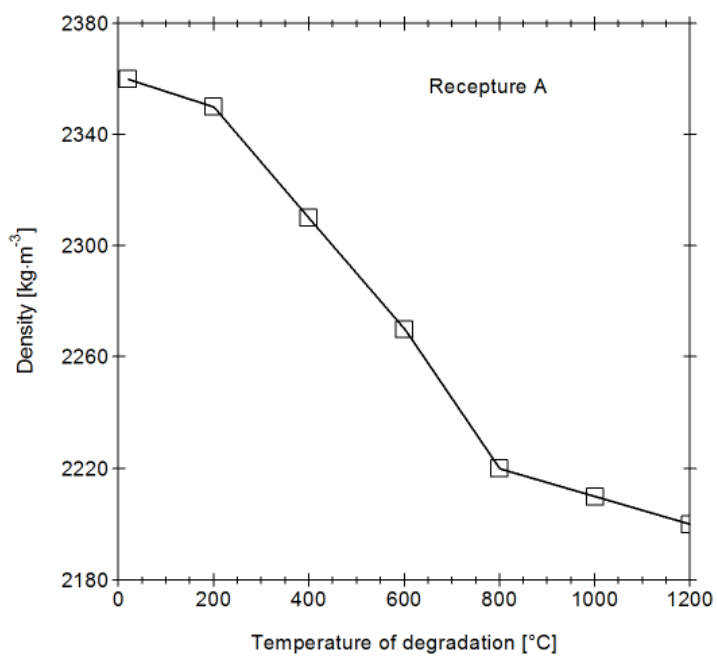

Fig. 7 The effect of a temperature on density of hardened concrete.

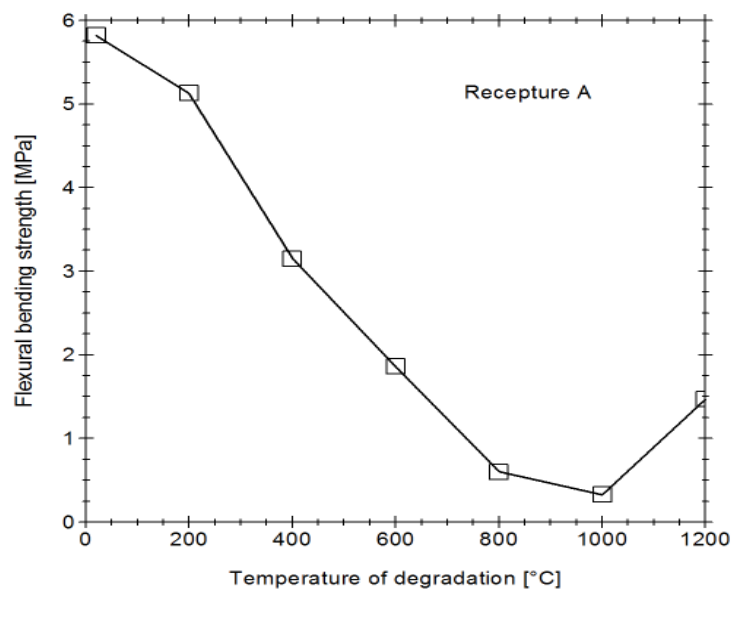

Fig. 8 The effect of a temperature on flexural bending strength. 
Concrete is a composite material. The main parts represent aggregates and cement matrix. An increasing temperature influences both the aggregate and the cement matrix. During heating the aggregates expand in volume, while the cement matrix shrinkages. These facts lead to formation of micro-cracks in the transition zone aggregate-cement paste. During heating of cement paste physically and chemically bound water is released, and cement hydration products is dehydrated (decomposition C-S-H gel, and portlandite). These processes contribute to an increase of porosity in the cement matrix and result in decreasing the density of the concrete (see Fig. 7). Increasing porosity, cracks in transition zone aggregate -cement paste, and decomposition hydration products leads to decreasing the mechanical properties of concrete [8] (see Fig. 8). It should be noted that the concrete samples were dried before heating. Therefore, there was no apparent significant decrease of concrete density at $200^{\circ} \mathrm{C}$, and no spalling occurred during heating.

\section{Conclusion}

The paper deals with analyzing the feasibility of concrete composite material of Portland Cement CEM I 42.5 R and gravel aggregate 8/16 testing by means of Impact-echo acoustic method. The specimens were intentionally degraded by application of elevated temperatures to $1200{ }^{\circ} \mathrm{C}$. A shift of the predominant frequencies was observed to occur during the degradation process.

Thus obtained results were compared with the changes in the bulk density and flexural bending strength of these specimens.

A strong correlation, which was disclosed between thus obtained results shows that the frequency inspection carried out by means of the Impact-echo method makes a convenient tool to assess the quality and life of these composite materials when exposed to elevated temperature.

\section{Acknowledgment}

This paper has been worked out under the project GA ČR No.1602261S supported by Czech Science Foundation.

\section{References}

[1] G. Epasto, E. Proverbio, V. Venturi, Evaluation of fire-damaged-concrete using impact-echo method, Mater. Struct. 43(1) (2010) 235-245.

[2] V. Garnier, B. Piwakowski, O. Abraham, G. Villain, C. Payan, J. P. Chaix, Acoustic techniques for concrete evaluation: Improvements, comparisonsnad consistency, Construct. Build. Mater. 43 (2013) 598-613.

[3] M. Korenska, Z. Chobola, R. Sokolar, P. Mikulkova, J. Martinek, Frequency inspection as an assessment tool for the frost resistance of fired roof tiles, Ceramics-Silikaty, 50 (3) (2006) 185-192.

[4] M. Krause, M. Barmann, R. Frielinghaus, et al., Comparison of pulse-echo methods for testing concrete, NDT \& E Int. 30(4) (1997) 195-204.

[5] M. T. Liang, P. J. Su, Detection of Corrosion Damage of Rebar in Concrete Using Impact-Echo Method, Cem. Concr. Res. 31(10) (2001) 1427-1436.

[6] M. Lunak, I. Kusak, Electric and Temperature Properties of Concrete Setting Measurement Set, Proc. of the Defektoskopie 2009 - NDE for Safety. Praha, BETIS, 2009, 269-274.

[7] M. Lunak, I. Kusak, L. Pazdera, L. Topolar, V. Bilek, Monitoring of cement-based material solidification, focusing on electrical properties, Proc. of the 48th International Scientific Conference Experimental Stress Analysis 2010, Olomouc, Palacky University, 2010, 233-240.

[8] L. Sitek, L. Bodnárová, J. Válek, M. Zeleňák, J. Klich, J. Foldyna, M. Novotný, Effects of water jet on heat-affected concretes, 11th International Scientific Conference on Modern Building 
Materials, Structures and Techniques, MBMST 2013; Vilnius; Lithuania; 16 May 2013 through 17 May 2013; Procedia Engineering, Vol. 57, 2013, pp. 1036-1044. 